\title{
Neuronal Nicotinic Receptor Expression in Sensory Neurons of the Rat Trigeminal Ganglion: Demonstration of $\alpha 3 \beta 4$, a Novel Subtype in the Mammalian Nervous System
}

\author{
Christopher M. Flores, ${ }^{1}$ Raquel M. DeCamp, ${ }^{1}$ Sonja Kilo, ${ }^{1}$ Scott W. Rogers, ${ }^{2}$ and Kenneth M. Hargreaves ${ }^{1}$ \\ ${ }^{1}$ Department of Restorative Sciences, University of Minnesota, Minneapolis, Minnesota 55455, and 2Salt Lake City \\ Veterans Administration-Geriatric Research Education Clinical Center and Department of Neurobiology and Anatomy, \\ University of Utah, Salt Lake City, Utah 84112
}

The identification of a family of neuronal nicotinic receptor subunit genes establishes the potential for multiple subtypes with diverse physiological functions. Virtually all of the high affinity nicotinic receptors measured to date in the rodent CNS are composed of $\alpha 4$ and $\beta 2$ subunits only. However, the demonstration of other subunit transcripts in a variety of central and peripheral nervous tissues suggests a greater degree of receptor subtype heterogeneity than so far has been elucidated. The purpose of the present studies was to determine at the mRNA and protein levels which neuronal nicotinic receptor subunits are expressed by sensory neurons of the rat trigeminal ganglion and in what combinations these gene products associate to form neuronal nicotinic receptor subtypes in this tissue. Radioreceptor binding analysis indicated that in the adult rat trigeminal ganglion there exist at least two nicotinic receptor binding sites with differing affinities for $\left[{ }^{3} \mathrm{H}\right]$-epibatidine. In situ hybrid- ization histochemical studies revealed the existence of mRNA encoding the $\alpha 3, \alpha 4, \alpha 5, \beta 2$, and $\beta 4$ subunits, but not the $\alpha 2$ subunit. Immunoprecipitation with subunit-specific antisera demonstrated that each of the subunits present in the ganglion at the mRNA level is a constituent of nicotinic receptors capable of binding ${ }^{3} \mathrm{H}$-epibatidine. Various applications of these approaches yielded strong evidence that, in addition to $\alpha 4 \beta 2$, which is thought to be the predominant neuronal nicotinic receptor subtype in the rodent CNS, trigeminal sensory neurons express as the principal subtype $\alpha 3 \beta 4$, which has not been demonstrated previously in mammalian nervous tissue.

Key words: nicotinic receptor subtype; sensory neurons; trigeminal ganglion; radioreceptor binding; $\left[{ }^{3} \mathrm{H}\right]$-epibatidine; immunoprecipitation; subunit composition; in situ hybridization; $m R N A$
Extensive investigations over the past 15 years have contributed to a better understanding of the structure, function, and regulation of neuronal nicotinic receptors in the central and peripheral nervous systems. Low stringency hybridization approaches using probes derived from the muscle $\alpha 1$ subunit has led to the cloning of seven $\alpha(\alpha 2-\alpha 7, \alpha 9)$ and three $\beta(\beta 2-\beta 4)$ rat neuronal subunit genes and the determination of their respective transcript distribution (Boulter et al., 1986, 1987, 1990; Goldman et al., 1987; Deneris et al., 1988, 1989; Wada et al., 1988, 1989; Duvoisin et al., 1989; Isenberg and Meyer, 1989; Lamar et al., 1990; Séguéla et al., 1993; Elgoyhen et al., 1994). In contrast to the $\alpha$-bungarotoxinbinding $\alpha 7$ or $\alpha 9$ subunit-containing receptors, which are each thought to arise via homo-oligomerization, available evidence suggests that neuronal nicotinic receptors that are insensitive to $\alpha$-bungarotoxin are composed of both agonist-binding $\alpha$ subunits

Received July 16, 1996; revised Sept. 25, 1996; accepted Oct. 1, 1996.

This work was funded by Grant 0490 from the Smokeless Tobacco Research Council and Grant DA10510 from National Institutes of Health. C.M.F. is supported by National Research Service Award Fellowship 5F32-DE05659 from National Institutes of Health. S.W.R. is funded by National Institutes of Health Grants NS30990 and AG04418 and a Veterans Administration Merit Award. We gratefully acknowledge Dr. Stephen Hurt of DuPont NEN for making $\left[{ }^{3} \mathrm{H}\right]$-epibatidine available and Dr. Jim Boulter of The Salk Institute for Biological Studies for generously providing the neuronal nicotinic receptor subunit cDNAs.

Correspondence should be addressed to Dr. Christopher M. Flores, University of Minnesota, 18-186 Moos Health Sciences Tower, 515 Delaware Street SE, Minneapolis, MN 55455.

Dr. Kilo is on leave from Institut für Physiologie und Experimentelle Pathophysiologie, Universitätstrasse 17, D-91054 Erlangen, Germany.

Copyright (C) 1996 Society for Neuroscience $0270-6474 / 96 / 167892-10 \$ 05.00 / 0$ (defined by consensus-paired cysteine residues) and structural $\beta$ subunits, purportedly manifesting a pentameric stoichiometry of two $\alpha$ and three $\beta$ subunits (Anand et al., 1991; Cooper et al., 1991). Receptor subtypes, therefore, would be defined by their subunit composition. Interestingly, all of the neuronal nicotinic binding sites so far identified in rat nervous tissue are composed of $\alpha 4$ and $\beta 2$ subunits (Whiting and Lindstrom, 1986, 1987; Whiting et al., 1987; Flores et al., 1992), which finding has been attributed to the restricted affinities of the available ligands used to detect these sites. Thus, although the mRNA encoding each of the cloned subunits has been demonstrated in various central and peripheral nervous structures, no receptor subtype other than $\alpha 4 \beta 2$ yet has been demonstrated directly in the mammalian nervous system.

Neuronal nicotinic receptors located on sensory neurons are far less well understood than those in the central or autonomic nervous systems in terms of their expression and function. So far, the presence of mRNA encoding the $\alpha 3, \alpha 4, \alpha 5$, and/or $\beta 2$ subunits has been demonstrated in rat trigeminal (Wada et al., 1989, 1990) and chick dorsal root (Boyd et al., 1991) ganglion. At the protein level, the $\beta 2$ subunit was identified immunohistochemically in the rat trigeminal ganglion (Swanson et al., 1987). Nonetheless, there has been, as yet, no reported demonstration of neuronal nicotinic binding sites in sensory ganglia of any vertebrate species. Strong evidence for their existence may be inferred from electrophysiological studies in cultured rat dorsal root (Sucher et al., 1990), trigeminal (Liu et al., 1993) and nodose (Baccaglini and Cooper, 1982; Mandelzys et al., 1990) ganglion 
neurons, which exhibited functional responses to nicotine or nicotinic agonists. These investigations, however, do not indicate primarily which of these mRNAs are translated into protein nor in what combinations the subunits associate to form native receptors. Thus, there is a clear rationale for more comprehensive investigations on the structure and function of these important neurotransmitter receptors on primary sensory neurons.

The rat trigeminal ganglion provides several advantages as a model system for the study of sensory neurons because of its size, accessibility, and innervation of defined peripheral targets. The purpose of the present investigation was to characterize the expression of neuronal nicotinic receptors in the rat trigeminal ganglion. Importantly, these studies were designed to examine six different subunits at both the mRNA and protein levels and to elucidate which of these gene products conjoin in forming potential receptor subtypes.

\section{MATERIALS AND METHODS}

Radioreceptor binding. Fresh frozen rat trigeminal ganglion tissue was

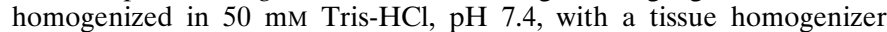
(Brinkmann, Westbury, NY) and washed twice by centrifugation at $48,000 \times g$ for $10 \mathrm{~min}$. The final pellet was resuspended in fresh buffer, and aliquots of homogenate equivalent to $20 \mathrm{mg}$ of tissue were added to test tubes containing buffer and various concentrations of $\left[{ }^{3} \mathrm{H}\right]$ epibatidine $(52 \mathrm{Ci} / \mathrm{mmol})$, which were synthesized by DuPont NEN (Wilmington, DE). Incubations were performed in a final volume of $0.25-5 \mathrm{ml}$ for $1 \mathrm{hr}$ at $25^{\circ} \mathrm{C}$. Longer incubations up to $4 \mathrm{hr}$ did not result in substantially different levels of binding in this tissue, indicating that, under these conditions, the binding reaction reached steady state. Nonspecific binding was determined in the presence of $300 \mu \mathrm{M}(-)$ nicotine bitartrate dihydrate (Sigma, St. Louis, MO). Incubations were terminated by rapid vacuum filtration through Whatman GF/C filter paper presoaked for $1 \mathrm{hr}$ in $0.5 \%$ polyethyleneimine and mounted on a cell harvester (Brandel, Gaithersburg, MD). The filters were washed rapidly three times with $4 \mathrm{ml}$ of cold assay buffer and then counted by liquid scintillation spectrometry.

Immunoprecipitation. Trigeminal ganglion tissue was prepared as above, and the final pellets were rehomogenized and incubated with $\left[{ }^{3} \mathrm{H}\right]$-epibatidine (1-10 nM). The mixture was solubilized with Triton $\mathrm{X}-100(2 \%)$ for $2 \mathrm{hr}$ and centrifuged $(48,000 \times g$ for $30 \mathrm{~min})$; aliquots of the resulting supernatants, equivalent to $30 \mathrm{mg}$ of original tissue weight, were incubated with polyclonal antisera raised against the $\alpha 2, \alpha 3, \alpha 4, \alpha 5$, $\beta 2$, or $\beta 4$ neuronal nicotinic receptor subunit (Rogers et al., 1991, 1992; Flores et al., 1992). After a $2 \mathrm{hr}$ incubation period, the mixture was immunoprecipitated with $100 \mu \mathrm{l}$ of a $10 \%$ suspension of stripped (Luthin et al., 1988) Pansorbin cells (Calbiochem, La Jolla, CA). The mixture was centrifuged, and the resulting pellet was washed with Tris-EDTA, dissolved in 3\% sodium deoxycholate, and counted by liquid scintillation spectrometry. For double immunoprecipitation studies, the supernatant from the last step above was incubated with a second antibody and precipitated as described.

cDNAs and probe synthesis. Plasmid constructs containing the cDNA clones encoding the $\alpha 2$ (HYP16; Wada et al., 1988), $\alpha 3$ (PCA48E; Boulter et al., 1986), $\alpha 4$ (HYA23; Goldman et al., 1987), $\alpha 5$ (PC1321; Boulter et al., 1990), $\beta 2$ (PCX49; Boulter et al., 1987; Deneris et al., 1988), and $\beta 4$ (ZPC13; Duvoisin et al., 1989) neuronal nicotinic receptor subunits were kindly provided by Dr. Jim Boulter (The Salk Institute for Biological Studies, La Jolla, CA). For probe synthesis, $1 \mu \mathrm{g}$ of plasmid DNA was linearized with the appropriate restriction endonuclease, and riboprobes were synthesized by in vitro transcription with a kit (Promega, Madison, WI) in the presence of either 11-biotin-UTP (Boehringer Mannheim, Indianapolis, IN) for nonisotopic probes or $250 \mu \mathrm{Ci}$ each of $\left[{ }^{35} \mathrm{~S}\right] \mathrm{CTP} \alpha \mathrm{S}$ and $\left[{ }^{35} \mathrm{~S}\right] \mathrm{UTP} \alpha \mathrm{S}$ (Amersham, Arlington Heights, IL) for isotopic probes at $37^{\circ} \mathrm{C}$ for $2 \mathrm{hr}$. Probes were purified by ethanol precipitation or G-50 spin column chromatography and stored at $-20^{\circ} \mathrm{C}$.

In situ hybridization histochemistry and immunocytochemistry. Trigeminal ganglia were freshly dissected, frozen on dry ice, immobilized in mounting medium, and cut as $20 \mu \mathrm{m}$ sections that then were mounted onto gelatin/chrom alum-coated glass slides and stored at $-80^{\circ} \mathrm{C}$. The sections were fixed for $1 \mathrm{hr}$ in a $4 \%$ formaldehyde solution, permeabilized with $0.5 \%$ Triton X-100, acylated with $0.0025 \%$ acetic anhydride in $0.1 \mathrm{M}$ triethanolamine, dehydrated, and delipidated in alcohol and chloroform. Then sections were hybridized with in vitro-transcribed $\left[{ }^{35} \mathrm{~S}\right]$-labeled riboprobes complimentary to mRNA encoding the $\alpha 2 \alpha 3, \alpha 4, \alpha 5, \beta 2$, or $\beta 4$ neuronal nicotinic receptor subunit. Slides were coverslipped with Parafilm and incubated at $55^{\circ} \mathrm{C}$ overnight. After RNase treatment and standard washing procedures, the tissue was blocked with $10 \%$ normal goat serum and then incubated in anti-peripherin primary antisera (Chemicon, Temecula, CA) overnight at $4^{\circ} \mathrm{C}$. Subsequent incubations with biotinylated secondary antibody, $\mathrm{ABC}$ reagents (Vector Laboratories, Burlingame, CA), and the colorimetric substrate diaminobenzidine (Sigma) were performed according to established procedures. Then the slides were subjected to emulsion autoradiography, counterstained, and coverslipped. Sense probes were used as controls. For double isotopic and nonisotopic in situ hybridization histochemistry, sections of rat trigeminal ganglion were prepared as above and hybridized simultaneously with an $\left[{ }^{35} \mathrm{~S}\right]$-labeled riboprobe complimentary to the $\alpha 3$ subunit and a biotinylated riboprobe complimentary to the $\beta 4$ subunit. After RNase treatment and high stringency washes, sections were blocked, incubated with streptavidin-conjugated alkaline phosphatase, and subjected sequentially to NTB/BCIP color development with a kit (Life Technologies, Grand Island, NY) and emulsion autoradiography as above.

Imaging. After processing the tissue sections as described above, we acquired images of various visual fields via a CCD-cooled camera, digitized them, and imported them into Adobe Photoshop using the facilities of the University of Minnesota Biomedical Imaging and Processing Laboratory (BIPL). Color prints of these images were obtained with a Fuji Pictography 3000 printer that uses lasers and photo emulsion but is not a dye sublimation or thermal printer.

\section{RESULTS}

\section{Heterogeneity of neuronal nicotinic receptor binding sites in the rat trigeminal ganglion}

Radioreceptor binding analyses were performed on membrane homogenates from rat trigeminal ganglia with $\left[{ }^{3} \mathrm{H}\right]$-epibatidine in a standard filtration assay. Data from saturation experiments were analyzed by nonlinear regression with LIGAND (Munson and Rodbard, 1980) and best fit a two-site model, consistent with the calculated Hill coefficient $\left(n_{\mathrm{H}}\right)$ of 0.72 . The two sites yielded $K_{\mathrm{D}}$ values of $\sim 518$ and 13 pM (Fig. 1 ) and corresponding $B_{\max }$ values of 0.5 and $0.2 \mathrm{fmol} / \mathrm{mg}$ tissue, respectively. Thus, the number of low affinity sites measured was $\sim 2.5$ times that of high affinity sites, with the total number of sites being linearly related to the amount of tissue assayed (data not shown). Specific binding, calculated as the difference between total binding and nonspecific binding in the absence and presence of $300 \mu \mathrm{M}$ nicotine bitartrate, respectively, was saturable and represented an average of $73.1 \%$ of the total binding across all concentrations of $\left[{ }^{3} \mathrm{H}\right]$-epibatidine tested (1.4 pM-3.9 nM). In addition, cytisine as well as nicotine effectively competed for $\left[{ }^{3} \mathrm{H}\right]$-epibatidine binding in this tissue in a concentration-dependent manner (data not shown). These data demonstrate the presence in the rat trigeminal ganglion of at least two neuronal nicotinic receptor binding sites, with different densities and markedly differing affinities for $\left[{ }^{3} \mathrm{H}\right]$-epibatidine, and are consistent with the existence of distinct receptor subtypes in this tissue.

\section{Multiple neuronal nicotinic receptor subunit genes are expressed by trigeminal sensory neurons at the mRNA and protein levels}

To determine which neuronal nicotinic receptor subunit mRNAs are expressed by the trigeminal ganglion, we conducted in situ hybridization analyses with ${ }^{35} \mathrm{~S}$-labeled antisense riboprobes complimentary to the mRNA encoding the $\alpha 2, \alpha 3, \alpha 4, \alpha 5, \beta 2$, or $\beta 4$ subunit. Figure 2 shows bright-field photomicrographs of $20 \mu \mathrm{m}$ sections of adult male rat trigeminal ganglia hybridized with one of the above probes. All sections also were processed immunocytochemically with an antibody specific for the type III intermedi- 

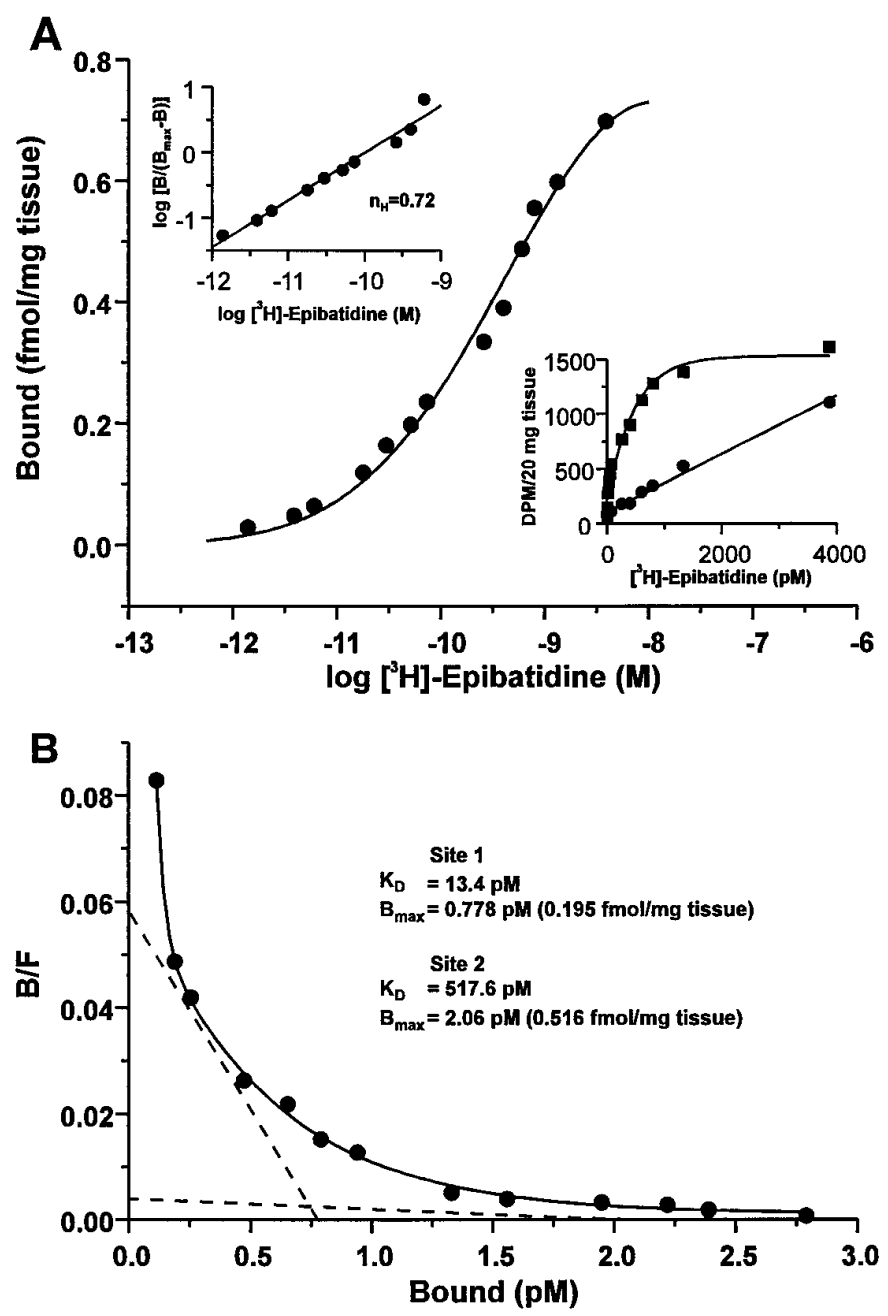

Figure 1. Neuronal nicotinic receptor binding sites in the rat trigeminal ganglion. Saturation binding analysis of neuronal nicotinic receptors labeled with $\left[{ }^{3} \mathrm{H}\right]$-epibatidine in membrane homogenates of rat trigeminal ganglion. Aliquots of homogenized, washed trigeminal ganglion membranes equivalent to $20 \mathrm{mg}$ of original tissue weight were incubated in triplicate with $\left[{ }^{3} \mathrm{H}\right]$-epibatidine at the indicated concentrations (1.4 pM to $3.9 \mathrm{nM}$ ) in the absence or presence of $300 \mu \mathrm{M}$ nicotine bitartrate (to define nonspecific binding). The median value of each triplicate measurement was used to generate all data. $A$, Semilog plot of the data expressed as bound receptor (fmol/mg tissue) and calculated as the difference between total and nonspecific binding. Top left inset, Hill plot, including the calculated Hill coefficient $\left(n_{\mathrm{H}}\right)$, of the transformed data. Bottom right inset, Linear plot of the specific (squares) and nonspecific (circles) binding at each concentration of $\left[{ }^{3} \mathrm{H}\right]$-epibatidine. $B$, Rosenthal plot of the data shown in $A$. Data were analyzed by nonlinear regression with LIGAND (Munson and Rodbard, 1980) and were best fit to a two-site model (ANOVA, $F_{1,8}=51.9 ; p<0.001$ ), as indicated by the dashed lines. The calculated receptor density $\left(B_{\max }\right)$ and equilibrium dissociation constant $\left(K_{\mathrm{D}}\right)$ values for each site are indicated. Data are representative of an experiment performed four times.

ate filament protein peripherin. Compared with sense controls (data not shown), hybridization to ganglion sections with antisense probes for the $\alpha 3, \alpha 4, \alpha 5, \beta 2$, and $\beta 4$ subunits (Fig. $2 B-F$ ) yielded various degrees of specific neuronal labeling. No abovebackground signal was detected for the $\alpha 2$ subunit (Fig. 2A). Grain densities for the $\alpha 3$ (Fig. 2B) or $\beta 4$ (Fig. 2F) subunits were similar, being very intense and localizing to $\sim 15 \%$ of the neurons. In contrast, grain densities in individual neurons were less concentrated for the $\alpha 4$ (Fig. 2C), $\beta 2$ (Fig. $2 E$ ), or, especially, $\alpha 5$ (Fig.
$2 D)$ subunit. Thus, compared with $\alpha 3$ and $\beta 4$, above-background labeling for each of these three subunits was much more diffuse, while localizing to a far greater proportion (ranging from 60 to $80 \%$ ) of neurons. Interestingly, most of the labeling observed for each subunit mRNA tested was detected in the large- and medium-diameter peripherin-negative neurons, suggesting that nicotinic receptors composed of these subunits are not expressed predominantly by small C-fiber neurons but are expressed primarily by large and medium neuronal populations, giving rise to $\mathrm{A} \beta$ and A $\delta$ fibers, respectively (Harper and Lawson, 1985). Differences in labeling intensity among subunits most probably reflect differences in the amount of each mRNA species present in this tissue and not differences in specific activity of the probes or other artifacts, because all of the probes were approximately the same length and all were synthesized and hybridized under the same conditions (see Materials and Methods for details). In addition, qualitatively identical results were obtained with a second set of probes generated against completely disparate regions of each transcript (data not shown). No specific labeling for any of the subunits was detected in the perineuronal satellite cells.

To ascertain at the protein level which subunits comprise neuronal nicotinic receptors expressed by the trigeminal ganglion, we conducted studies using subunit-specific antisera to immunoprecipitate $\left[{ }^{3} \mathrm{H}\right]$-epibatidine-labeled receptors from aliquots of solubilized membrane homogenates. The antisera used here were generated against structurally homologous (C-terminal intracellular loop), but nonidentical, epitopes of each subunit. Importantly, each serum is capable of exclusively recognizing by either Western blot or ELISA only the subunit fusion protein against which it was produced (Rogers et al., 1992). In addition, successful and exclusive immunoprecipitation, as well as immunocytochemistry, was obtained for $\alpha 2, \alpha 3$, and $\beta 2$ antisera in transfected Rat 2 cells (Rogers et al., 1991), and each subunit that has been identified in PC1 2 cells at the mRNA level $(\alpha 3, \alpha 5, \beta 2$, and $\beta 4$, but not $\alpha 2$ or $\alpha 4)$ was detected faithfully in these cells immunocytochemically (Rogers et al., 1992). Similarly, in P19 cells exposed to retinoic acid, there was perfect concordance between Northern blot analyses and immunocytochemical studies demonstrating the expression at the mRNA and protein levels, respectively, of $\alpha 3, \alpha 4$, and $\beta 2$ subunits in these cells (Cauley et al., 1996). Finally, the anti- $\beta 4$ serum immunohistochemically localized its respective subunit to specific cell types in the ground squirrel retina, exhibiting a cellular distribution pattern that was confirmed by in situ hybridization for $\beta 4$ subunit mRNA (Britto et al., 1994). Collectively, these data indicate that each of the sera being used for the present studies is specific and competent, such that any signal (measured as precipitated $\left[{ }^{3} \mathrm{H}\right]$-epibatidine-labeled receptor) obtained for a given serum would be representative of the subunit against which it was generated (i.e., not a false positive); conversely, any lack of signal obtained for a given serum would indicate the absence of its respective subunit in forming neuronal nicotinic receptors (with sufficient affinity for $\left[{ }^{3} \mathrm{H}\right]$-epibatidine that it would be detected) and would not be a result of the inability of that serum to interact with its respective subunit (i.e., not a false negative).

Figure 3 illustrates immunoprecipitation data from aliquots of solubilized, $\left[{ }^{3} \mathrm{H}\right]$-epibatidine-labeled rat trigeminal ganglion membranes, in which specific immunoprecipitation is calculated as the difference between total immunoprecipitation, obtained with a subunit-specific serum, and nonspecific immunoprecipitation, obtained with normal rabbit serum (NRS). It has been shown previously that nonspecific immunoprecipitation is approximately the same whether it is determined by this 

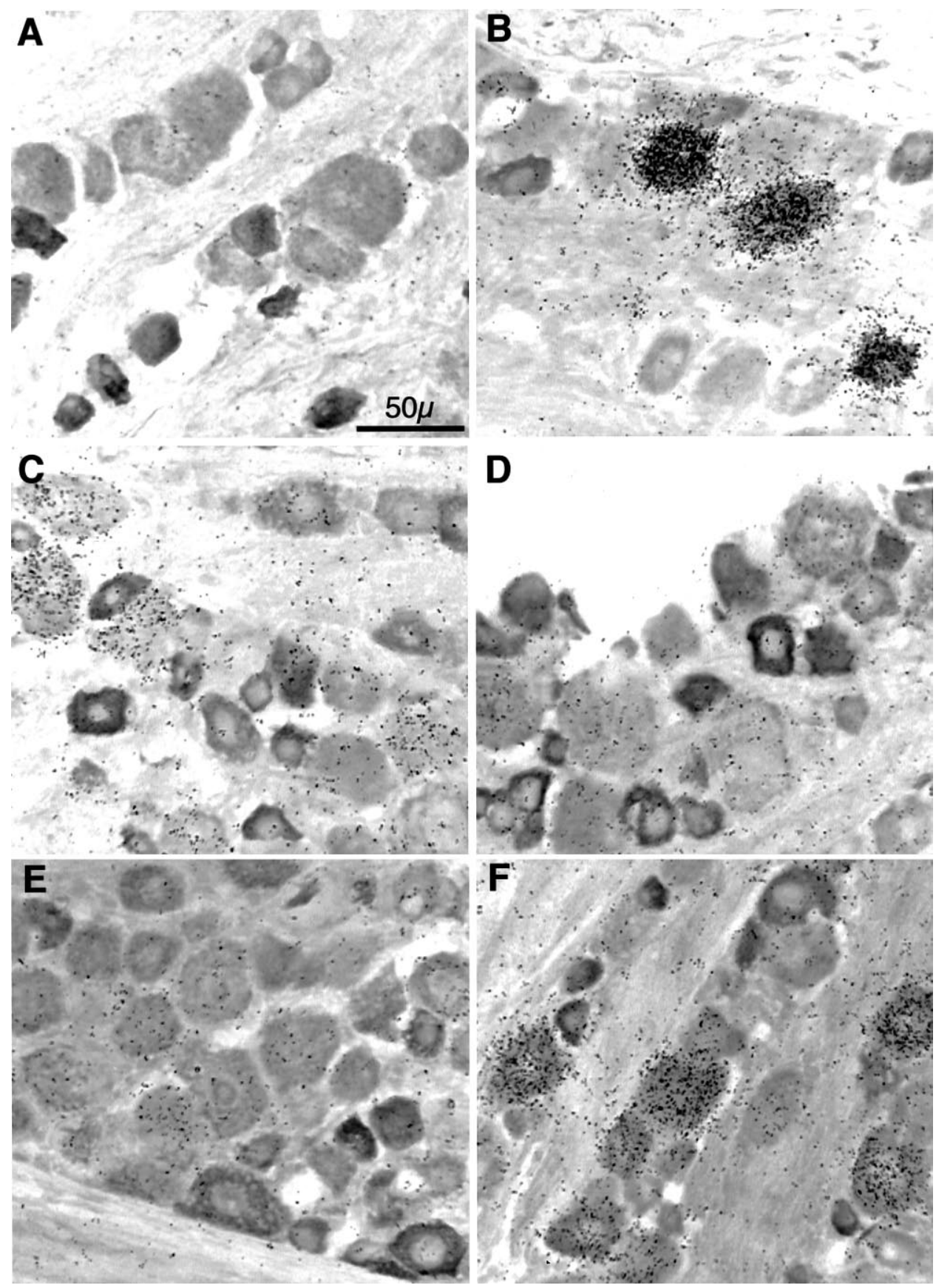

Figure 2. Neuronal nicotinic receptor subunit mRNA expression in sensory neurons of the rat trigeminal ganglion. Combined in situ hybridization histochemistry and immunocytochemistry for neuronal nicotinic receptor subunit mRNAs and peripherin in the rat trigeminal ganglion. Bright-field images are of $20-\mu \mathrm{m}$-thick frozen sections of adult male rat trigeminal ganglion sequentially processed for in situ hybridization by a ${ }^{35} \mathrm{~S}$-labeled riboprobe complimentary to the mRNA encoding the $\alpha 2(A), \alpha 3(B), \alpha 4(C), \alpha 5(D), \beta 2(E)$, or $\beta 4(F)$ neuronal nicotinic receptor subunit (represented by black grains), followed by immunocytochemistry with an anti-peripherin rabbit serum (seen as darkly stained cells). After ABC (peroxidase) color development, slides were subjected to emulsion autoradiography, counterstained, coverslipped, and photographed. Total magnification, $40 \times$; scale is indicated in $A$. Photographs are representative of experiments performed at least five times for each subunit transcript with two separate and nonoverlapping probes.

method, by preimmune serum, or by immune serum in the presence of excess cold nicotine (Flores et al., 1992). These data indicate that the highest amounts of labeled receptor are precipitated with sera specific for the $\alpha 3$ and $\beta 4$ subunits, yielding $743.8 \pm 94.8$ and $796.8 \pm 79.6 \mathrm{dpm}$, respectively. In addition, lower amounts of receptor were precipitated with sera specific for the $\alpha 4$ and $\beta 2$ subunits, yielding $235.2 \pm 44.4$ and $323.2 \pm 40.0 \mathrm{dpm}$, respectively. Low but detectable immunoprecipitation was obtained for $\alpha 5(49.9 \pm 52.4 \mathrm{dpm})$, while virtually no specific immunoprecipitation was obtained for $\alpha 2$ $(0.9 \pm 14.4 \mathrm{dpm})$. Interestingly, the number of receptor binding sites containing $\alpha 3$ or $\beta 4$ subunits is approximately equal, as is the number of receptor binding sites containing $\alpha 4$ or $\beta 2$ subunits, with there being 2.8 times as many of the former pair of subunits as the latter pair of subunits. Taken together, these results are consistent with the hypothesis that $\alpha 3$ and $\beta 4$ subunits associate to form one neuronal nicotinic receptor subtype and that $\alpha 4$ and $\beta 2$ subunits associate to form a second subtype. In contrast, $\alpha 2$ subunits apparently do not participate in the formation of neuronal nicotinic receptors in this tissue. The potential contribution of $\alpha 5$ subunits is less clear and will be discussed below.

What is not evident from the previous data is whether these two potential subtypes (i.e., $\alpha 3 \beta 4$ and $\alpha 4 \beta 2$ ) represent the two classes of binding site described in Figure 1. If this were true, then one would predict that the apparent affinities of each would be similar. In an attempt to determine the dissociation constants of specific subunit-containing receptors, we performed saturation binding analyses in the context of the immunoprecipitation paradigm. Thus, aliquots of solubilized trigeminal ganglion membrane ho- 


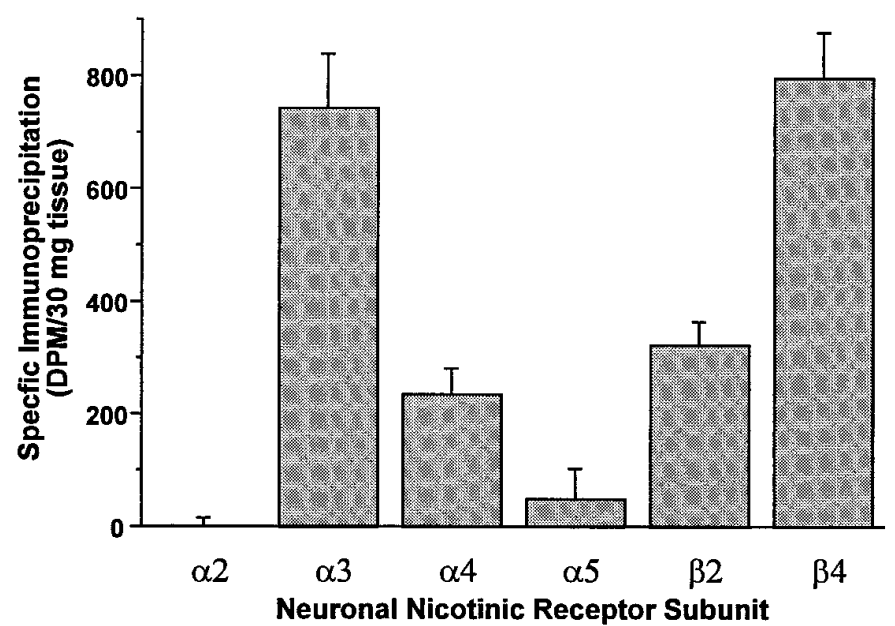

Figure 3. Subunit constituents of neuronal nicotinic receptors in the rat trigeminal ganglion. Immunoprecipitation of neuronal nicotinic receptors from rat trigeminal ganglion. Aliquots of $\left[{ }^{3} \mathrm{H}\right]$-epibatidine-labeled, Triton $\mathrm{X}-100$-solubilized rat trigeminal ganglion membranes equivalent to $30 \mathrm{mg}$ of original tissue weight were incubated with rabbit antisera specific for each of the neuronal nicotinic receptor subunits indicated or normal rabbit serum (NRS) and precipitated with Pansorbin cells by centrifugation. Specific immunoprecipitation was calculated to be the difference between that obtained with each subunit-specific serum and that obtained with NRS. Data from three to seven experiments are expressed as the mean $\pm \mathrm{SEM}$ in $\mathrm{dpm} / 30 \mathrm{mg}$ tissue.

mogenates, equivalent to $30 \mathrm{mg}$ of original tissue weight, were incubated with varying concentrations of $\left[{ }^{3} \mathrm{H}\right]$-epibatidine. Then these aliquots were precipitated with antisera specific for the $\alpha 3$, $\alpha 4, \beta 2$, or $\beta 4$ subunit or NRS to define nonspecific immunoprecipitation, and specific immunoprecipitation was calculated as described above. The data from these experiments were analyzed again by nonlinear regression and are depicted in Figure 4. Each of the four panels presents the data as semilog plots of specific immunoprecipitation as a function of increasing concentrations of $\left[{ }^{3} \mathrm{H}\right]$-epibatidine. For each panel, the top left and bottom right insets represent, respectively, Hill and Rosenthal plots of the transformed data. For each subunit, the data were best fit to a single site, as indicated by Hill coefficients $\left(n_{\mathrm{H}}\right)$ near unity and linear Rosenthal plots. Importantly, maximal immunoprecipitation as well as the calculated $K_{\mathrm{D}}$ values for the $\alpha 3$ and $\beta 4$ subunits (top panels) were approximately equal, 686.0 versus $635.8 \mathrm{dpm} / 30$ $\mathrm{mg}$ of tissue and 566 versus $441 \mathrm{pm}$, respectively. Similarly, maximal immunoprecipitation and calculated $K_{\mathrm{D}}$ values for the $\alpha 4$ and $\beta 2$ subunits (bottom panels) were approximately equal, 175.9 versus $188.5 \mathrm{dpm} / 30 \mathrm{mg}$ of tissue and 99 versus $58 \mathrm{pM}$, respectively. Although immunoprecipitation by this method is consistently reproducible in this tissue, it is incomplete. This is most likely attributable to the efficiency of solubilization, because maximal specific binding of this receptor in solubilized trigeminal tissue is $\sim 35 \%$ of that in homogenates; it is important to note, therefore, that the amount of solubilized receptor measured under these conditions is linear with respect to the amount of tissue (data not shown). In addition, the maximal amount of immunoprecipitation for either $\alpha 3$ or $\beta 4$ plus that for either $\alpha 4$ or $\beta 2$ yields $\sim 100 \%$ of the amount of total solubilized receptor, suggesting that subtypes composed of these subunit pairs potentially can account for all of the nicotinic receptors measured under these conditions. Nonetheless, although it is possible to compare relative maximal immunoprecipitation values for each subunit as described above, it is not possible to determine the true and absolute $B_{\max }$ values in this type of experiment. In contrast, the calculated $K_{\mathrm{D}}$ values from this type of experiment may be compared directly with those obtained using the saturation binding analyses presented in Figure 1. Thus, it is notable that the dissociation constants obtained for the $\alpha 3$ and $\beta 4$ subunits are nearly identical to that obtained for the low affinity site (i.e., $517.6 \mathrm{pm}$ ), and those obtained for the $\alpha 4$ and $\beta 2$ subunits are reasonably close to that for the high affinity site in Figure 1 (i.e., $13.4 \mathrm{pm}$ ). Differences in the calculated $K_{\mathrm{D}}$ values of the high affinity site between the two approaches are likely a result of the rather low number of these sites measured, leading to large variations in the regression analyses conducted on the data from the two experimental conditions. These data, therefore, support the hypothesis that $\alpha 3$ and $\beta 4$ subunits associate to form the low affinity neuronal nicotinic receptor subtype and that $\alpha 4$ and $\beta 2$ associate to form the high affinity subtype.

\section{Subunit composition of neuronal nicotinic receptors in the rat trigeminal ganglion: direct evidence for $\alpha 3 \beta 4$ and $\alpha \mathbf{4} \beta 2$ subtypes}

To elucidate the subunit composition of neuronal nicotinic receptor subtypes present in the trigeminal ganglion and as a direct test of the above stated hypothesis, we used a double immunoprecipitation protocol. The rationale for these studies holds that if preincubation with one antiserum leads to a decrease in the amount of specific immunoprecipitation obtained on subsequent incubation with a second antiserum, then there must be a physical association between the subunits for which the two sera are specific. This approach has been used previously to demonstrate that the predominant, and possibly only, neuronal nicotinic receptor subtype labeled with $\left[{ }^{3} \mathrm{H}\right]$-cytisine in the rat CNS is composed of $\alpha 4$ and $\beta 2$ subunits (Flores et al., 1992). Thus, in the present study, aliquots of solubilized, $\left[{ }^{3} \mathrm{H}\right]$-epibatidine-labeled receptors from rat trigeminal ganglion membrane homogenates, equivalent to $30 \mathrm{mg}$ of original tissue weight, were precleared with one antibody, and the resulting supernatants were subjected to an additional round of immunoprecipitation with a second antibody. The data are expressed as the percentage immunoprecipitated after the first antibody according to the following formula:

$$
\begin{aligned}
& \text { (specific immunoprecipitation obtained } \\
& \frac{\text { after preclearing with SRS) }}{\text { (specific immunoprecipitation obtained }} \\
& \quad \text { after preclearing with NSR) }
\end{aligned}
$$

in which SRS is one of the subunit-specific antibodies, NRS is normal rabbit serum, and specific immunoprecipitation is calculated as described previously. By definition, the positive control for such an experiment dictates that a given antiserum substantially would abolish subsequent immunoprecipitation by itself.

The results from this experiment (Fig. 5) demonstrate that preclearing with anti- $\alpha 3$ serum (first set of bars) led to an $80 \%$ reduction in the subsequent immunoprecipitation by itself. Moreover, preclearing with this serum reduced to a similar level subsequent immunoprecipitation with anti- $\beta 4$ serum, indicating that these two subunits do indeed associate in forming one neuronal nicotinic receptor subtype. Subsequent immunoprecipitation with anti- $\alpha 4$ or anti- $\beta 2$ sera was affected only slightly, being reduced by $\sim 5$ and $30 \%$, respectively. Although it is difficult to assess whether such small reductions may reflect actual subunit associations according to the above-stated rationale, it may be appreciated that there is a clear bimodal distribution of the data, such that pre- 

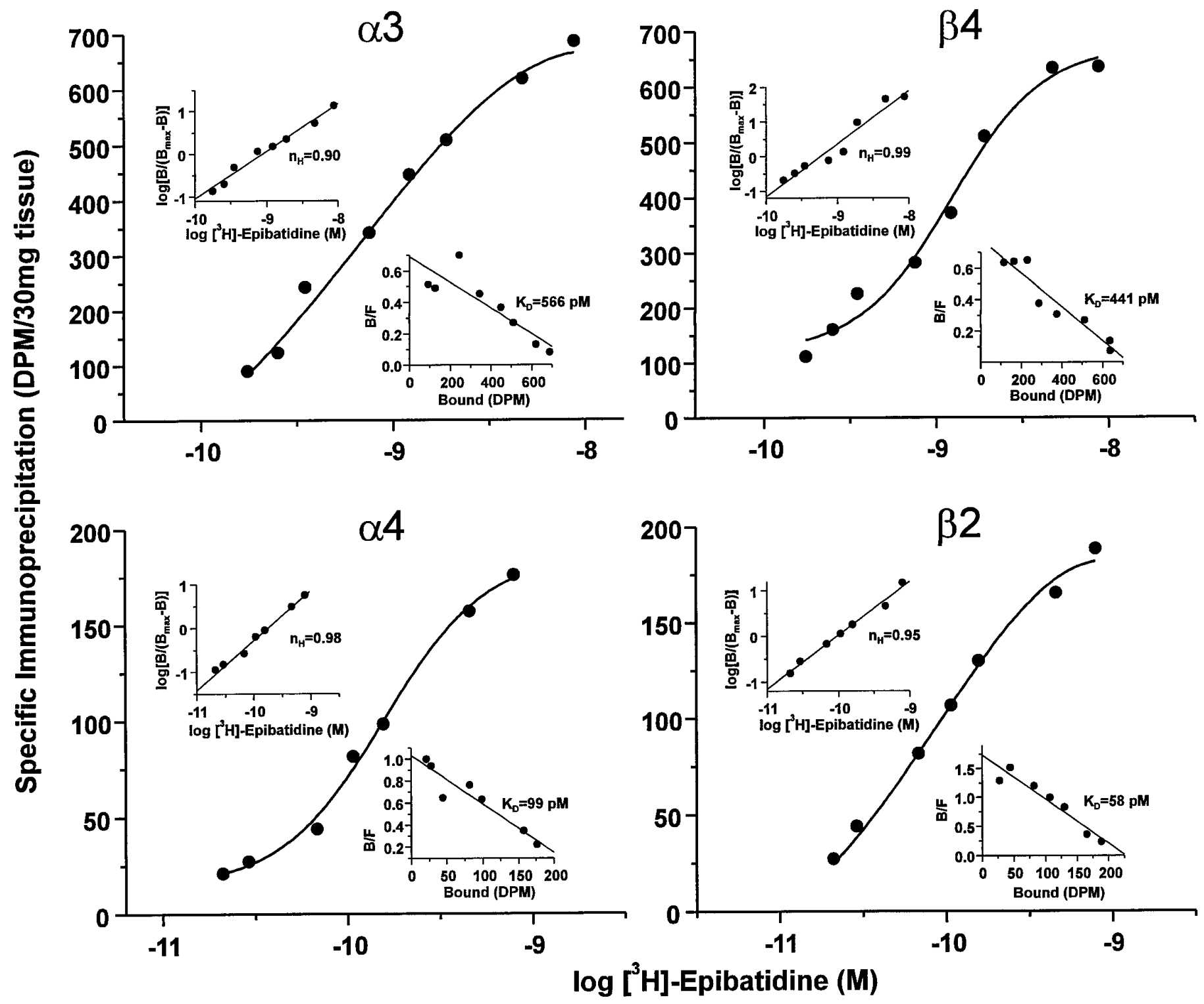

Figure 4. Binding parameters of neuronal nicotinic receptor subtypes in the rat trigeminal ganglion. Saturation binding analysis of neuronal nicotinic receptors labeled with $\left[{ }^{3} \mathrm{H}\right]$-epibatidine and immunoprecipitated with subunit-specific rabbit antisera. Aliquots of Triton X-100-solubilized rat trigeminal ganglion membranes equivalent to $30 \mathrm{mg}$ of original tissue weight were labeled with $\left[{ }^{3} \mathrm{H}\right]$-epibatidine at the indicated concentrations $(0.175-8.7 \mathrm{nM}$ for $\alpha 3$ and $\beta 4 ; 29-792 \mathrm{pm}$ for $\alpha 4$ and $\beta 2$ ), incubated with rabbit antisera specific for each of the neuronal nicotinic receptor subunits indicated or normal rabbit serum (NRS), and then precipitated with Pansorbin cells by centrifugation. Specific immunoprecipitation was calculated to be the difference between that obtained with each subunit-specific serum and that obtained with NRS at each concentration of [ $\left.{ }^{3} \mathrm{H}\right]$-epibatidine. Each quadrant depicts a semilog plot of the data for each of the four antisera tested, expressed as specific immunoprecipitation in dpm/30 mg of tissue. Top left insets, Hill plot, including the calculated Hill coefficient $\left(n_{\mathrm{H}}\right)$, of the transformed data. Bottom right insets, Rosenthal plots, including calculated equilibrium dissociation constant $\left(K_{\mathrm{D}}\right)$ values, of the transformed data. Data were analyzed by nonlinear regression with LIGAND (Munson and Rodbard, 1980) and, for each subunit, were best fit to a one-site model as indicated by the single solid lines (circles). Because of the tremendous amounts of tissue, radioactivity, and antibody required, this experiment was performed only once.

clearing with anti- $\alpha 3$ serum has a visibly greater ability to reduce subsequent immunoprecipitation by itself and anti- $\beta 4$ serum, as compared with anti- $\alpha 4$ or anti- $\beta 2$ serum. Such an interpretation is supported strongly by all of the data, and, in fact, this type of bimodal distribution is observed similarly for these subunit pairs throughout the experiment (see below). Thus, preclearing with anti- $\beta 4$ serum (fourth set of bars) led to a $>95 \%$ reduction in the subsequent immunoprecipitation by itself as well as a substantial $80 \%$ reduction in that obtained with anti- $\alpha 3$ serum. This also strongly supports the association of this subunit pair in forming an $\alpha 3 \beta 4$ receptor subtype. Here again, preclearing with anti- $\beta 4$ se- rum led to lower, 20 and $40 \%$, reductions in subsequent immunoprecipitation with anti- $\alpha 4$ and anti- $\beta 2$ sera, respectively. However, the difference in magnitude of these reductions compared with that for $\alpha 3$ and $\beta 4$ is clearly evident.

Preclearing with anti- $\alpha 4$ serum (second set of bars) almost completely abolished subsequent immunoprecipitation by itself and reduced by $60 \%$ that for anti- $\beta 2$. Subsequent immunoprecipitation by anti- $\alpha 3$ or anti- $\beta 4$ serum, on the other hand, was unaffected. Consistent with this finding, preclearing with anti- $\beta 2$ serum (third set of bars) led to an $\sim 80 \%$ reduction in subsequent immunoprecipitation by itself and a similar reduction in that by 


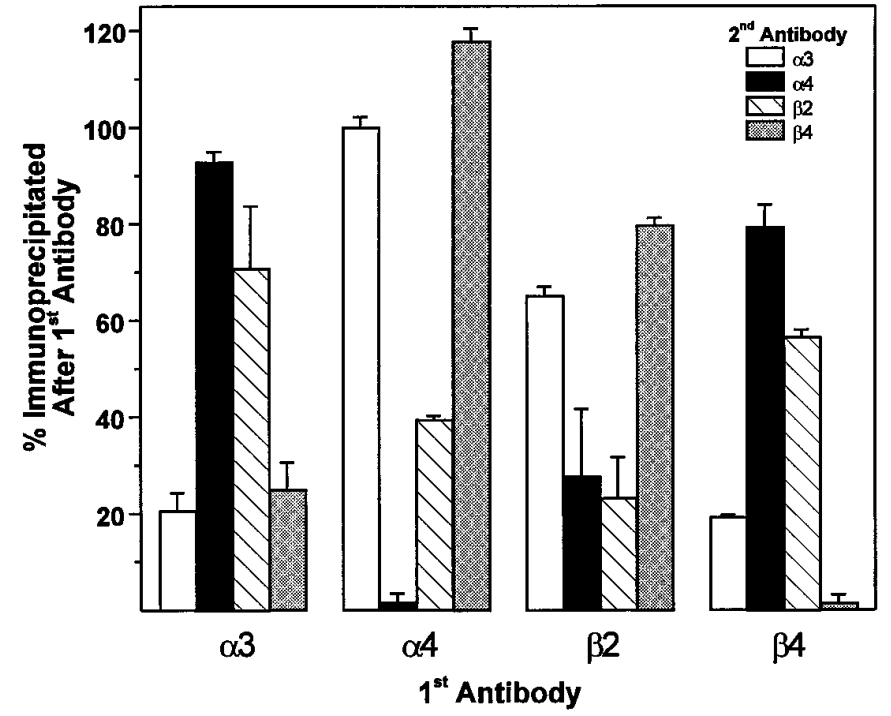

Figure 5. Subunit composition of neuronal nicotinic receptor subtypes in the rat trigeminal ganglion. Double immunoprecipitation of neuronal nicotinic receptors from rat trigeminal ganglion. Aliquots of $\left[{ }^{3} \mathrm{H}\right]-$ epibatidine-labeled, Triton X-100-solubilized rat trigeminal ganglion membranes equivalent to $30 \mathrm{mg}$ of original tissue weight were incubated with rabbit antisera specific for each of the neuronal nicotinic receptor subunits (indicated on the abscissa as 1st Antibody) or normal rabbit serum (NRS) and precipitated with Pansorbin cells by centrifugation. The resulting supernatant was reprecipitated in triplicate with a second antibody (indicated by the inset as 2nd Antibody). Data (mean \pm SEM) are expressed as the percentage immunoprecipitated after the first antibody, which was calculated as the ratio of the amount of specific immunoprecipitation obtained by the second antibody after preclearing with the first antibody divided by the amount of specific immunoprecipitation obtained by the second antibody after preclearing with NRS (see text for rationale and interpretation). Data are representative of an experiment performed four times.

anti- $\alpha 4$ serum. Much smaller reductions of $20-30 \%$ were observed on subsequent immunoprecipitation with anti- $\alpha 3$ and anti- $\beta 4$ sera. Collectively, these data demonstrate that $\alpha 4$ and $\beta 2$ subunits associate to form a second neuronal nicotinic receptor subtype. A more thorough analysis of these results will be taken up in Discussion.

\section{$\alpha 3$ and $\beta 4$ subunit mRNAs are coexpressed in individual sensory neurons of the rat trigeminal ganglion}

If certain subunits do, indeed, associate in forming a given receptor subtype, then the mRNA encoding those subunits should be coexpressed in the same cell. Because $\alpha 4$ and $\beta 2$ subunit mRNAs both were found in greater than one-half of the neurons in the trigeminal ganglion, then there necessarily should be some neurons that coexpress the two. However, $\alpha 3$ and $\beta 4$ subunit mRNAs each localized to only $\sim 15 \%$ of neurons; thus, it would be important to determine whether these populations of cells overlapped. To examine this possibility, we performed double in situ hybridizations using isotopic and nonisotopic probes on the same sections of rat trigeminal ganglion tissue. Figure 6 shows representative bright-field $(A)$ and epi-polarized $(B)$ photomicrographs of the same section of tissue that was hybridized simultaneously with both an ${ }^{35}$ S-labeled riboprobe complimentary to the $\alpha 3$ subunit mRNA and also a biotinylated riboprobe complimentary to the $\beta 4$ subunit mRNA. Then tissue sections were subjected to sequential ABC (alkaline phosphatase) color development and emulsion
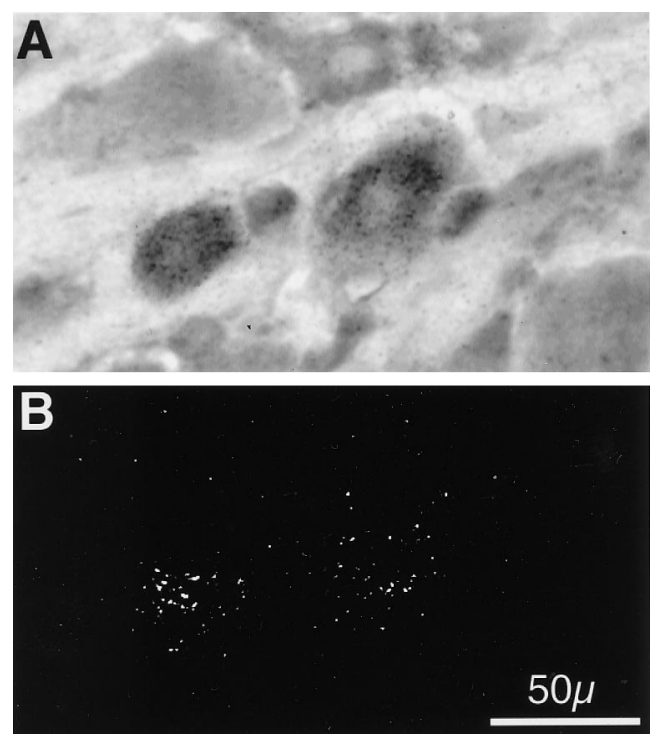

Figure 6. Colocalization of $\alpha 3$ and $\beta 4$ mRNA in individual neurons of the rat trigeminal ganglion. Double isotopic and nonisotopic in situ hybridization histochemistry for $\alpha 3$ and $\beta 4$ neuronal nicotinic receptor subunit mRNAs in the rat trigeminal ganglion. Bright-field $(A)$ and epi-polarized $(B)$ images are of the same $20-\mu \mathrm{M}$-thick frozen section of adult male rat trigeminal ganglion simultaneously hybridized with a ${ }^{35} \mathrm{~S}$-labeled riboprobe complimentary to the mRNA encoding the $\alpha 3$ subunit (represented by black grains in $A$ and white grains in $B$ ) and a biotinylated riboprobe complimentary to the $\beta 4$ subunit (seen as darkly stained cells in $A$ ). After $\mathrm{ABC}$ (alkaline phosphatase) color development, slides were subjected to emulsion autoradiography, coverslipped, and photographed. Total magnification, $40 \times$; scale is indicated in $B$. Photographs are representative of an experiment performed three times.

autoradiography. In the section shown, four cells (2 large and 2 small) exhibited nonisotopic labeling (darkly stained cells across the center of Fig. $6 A$ ) indicative of the presence of $\beta 4$ mRNA in these neurons. In addition, several neurons of varying sizes are unlabeled. It is clearly evident that the two large cells also have been labeled isotopically (white grains in Fig. $6 B$ ) indicative of the expression of $\alpha 3$ mRNA. Such double labeling of cells was common in several sections of tissue obtained from separate animals, indicating that the mRNA encoding the $\alpha 3$ and $\beta 4$ subunits is coexpressed in individual sensory neurons of the rat trigeminal ganglion and is consistent with the above data demonstrating association of the two subunits at the protein level.

\section{DISCUSSION}

Previous studies in rat brain and spinal cord have demonstrated that virtually all neuronal nicotinic receptors labeled by $\left[{ }^{3} \mathrm{H}\right]-$ cytisine in these tissues are composed of $\alpha 4$ and $\beta 2$ subunits (Flores et al., 1992). This finding was somewhat unexpected, given the diverse array of nicotinic receptor subunit mRNAs known to be expressed throughout the rat CNS (Wada et al., 1989). However, a number of explanations have been offered to clarify this discrepancy, the most likely of these being that certain neuronal nicotinic receptors composed of subunits other than $\alpha 4$ and $\beta 2$ do not possess sufficiently high affinity for the radioligands traditionally used to measure them that they would be detected. However, a novel high affinity radioligand called $\left[{ }^{3} \mathrm{H}\right]$-epibatidine has been used to identify specifically two nicotinic cholinergic receptor binding sites in rat and human brain (Houghtling et al., 1994, 1995), suggesting that this ligand is capable of detecting multiple receptor subtypes. In the present studies, we have used $\left[{ }^{3} \mathrm{H}\right]-$ 
epibatidine, in conjunction with a battery of subunit-specific antisera and cDNAs, to demonstrate that the predominant neuronal nicotinic receptor subtype expressed by rat trigeminal sensory neurons is $\alpha 3 \beta 4$. In addition, these neurons also express, albeit at lower levels, the high affinity $\alpha 4 \beta 2$ subtype known to predominate in the rat CNS.

Importantly, the present studies invoke converging lines of evidence at both the protein and mRNA levels to establish which subunits are expressed by trigeminal sensory neurons and in what combinations they associate to form multiple receptor subtypes. The initial step in this process used radioreceptor binding analyses with $\left[{ }^{3} \mathrm{H}\right]$-epibatidine to demonstrate directly the existence of multiple neuronal nicotinic receptor binding sites in the rat trigeminal ganglion (Fig. 1). Indeed, the results presented here are remarkably similar to those obtained for the two sites recently elucidated in rat brain $\left(K_{\mathrm{D}}\right.$ values $=$ 360 and 15 pM, respectively; Houghtling et al., 1995). The unique properties of this recently available radioligand, including its high affinity and specificity, seem to have overcome, at least partially, some of the impediments to the elucidation of nicotinic receptor subtype heterogeneity.

In situ hybridization histochemical analyses were used to determine which subunit mRNAs are expressed by the sensory neurons, the somata of which reside in the trigeminal ganglion (Fig. 2). These investigations extend those previously performed in that the present data were analyzed microscopically at the single-cell level and combined the simultaneous immunohistochemical localization of peripherin, a relatively selective neuronal marker for the peripheral nervous system (Parysek and Goldman, 1988). Interestingly, each of the subunit mRNAs detected, especially $\alpha 3$ and $\beta 4$, seemed to localize predominantly, although not exclusively, to the large- and medium-diameter peripherin-negative neurons. Peripherin is a type III intermediate filament protein that has been shown to be localized selectively to small-diameter peptidergic sensory neurons within the dorsal root (Goldstein et al., 1991) and trigeminal (Flores et al., 1993) ganglia. This cellular distribution of neuronal nicotinic receptors, then, may offer some clues as to their physiological significance in vivo (see below).

Immunoprecipitation of receptors with subunit-specific antisera (Fig. 3) indicated that the expression of each subunit mRNA in the trigeminal ganglion was reflected at the protein level. Given that the specific immunoprecipitation obtained for $\alpha 3$ or $\beta 4$ was approximately equal, as was that obtained for $\alpha 4$ or $\beta 2$, and that there was $\sim 2.5$ times as much of the former subunit pair as the latter, it was attractive to hypothesize that these subunit pairs give rise to two distinct nicotinic receptor subtypes and that these subtypes represent the two classes of binding sites detected by $\left[{ }^{3} \mathrm{H}\right]$-epibatidine. The relatively good accordance between the $K_{\mathrm{D}}$ values and proportional receptor densities obtained in the immunoprecipitation saturation experiment (Fig. 4) and those obtained in the standard radioreceptor assay (Fig. 1) offer compelling evidence for the concept that, in the rat trigeminal ganglion, an $\alpha 3 \beta 4$ subtype constitutes the low affinity, high density site and an $\alpha 4 \beta 2$ subtype constitutes the high affinity, low density site.

As a direct test of these specific subunit interactions, we performed double immunoprecipitation experiments (Fig. 5), an approach that was used previously to identify the $\alpha 4 \beta 2$ subtype in the rat CNS (Flores et al., 1992). As mentioned above, the small decreases in $\alpha 3$ and $\beta 4$ precipitation resulting from depletion by anti- $\beta 2$ serum, for example, suggest that the postulation of only two receptor subtypes in this tissue, namely $\alpha 3 \beta 4$ and $\alpha 4 \beta 2$, may be oversimplified. Indeed, the data are consistent with there being an additional $\alpha 3 \beta 2$ subtype, and the potential existence of small amounts of receptors composed of all possible subunit combinations cannot be ruled out. Presumably, radioreceptor binding assays would not detect such small proportions of these subtypes if, indeed, they do exist and especially if they would possess similar affinities to those exhibited by $\alpha 3 \beta 4$ or $\alpha 4 \beta 2$.

The possibility of a random association of all or several subunits, however, might seem untenable in light of the substantial evidence that certain signals are encoded into the subunits that govern their assembly into native nicotinic receptors (Sumikawa and Nishizaki, 1994). Thus, a prescribed and dedicated association of certain subunits would limit the number of subtypes possible. Indeed, the process of patterned subunit polymerization may be a generalized phenomenon governing the assembly of ligand-gated ion channel receptors, because it has been found that the formation of $\mathrm{GABA}_{\mathrm{A}}$ receptors from multiple subunits observes a preferred configuration rather than random association (Angelotti and Macdonald, 1993). Whether or not state-dependent subunit assembly would occur, suggesting a degree of plasticity in the system and a consequently greater number of potential subtypes, is unknown.

Another explanation for our findings is that a portion of the subunit combinations detected may form an additional association with $\alpha 5$, although the low amount of specific immunoprecipitation obtained for this subunit precludes our ability to test directly this possibility via the current approach. Such a scenario has been observed, however, in chick ciliary ganglion in which $\alpha 3$ and $\beta 4$ subunits were found in association with $\alpha 5$ subunits (Conroy and Berg, 1995). In fact, these studies indicated that $\sim 20 \%$ of the nicotinic receptors in this tissue contained a fourth subunit $\beta 2$, suggesting that certain populations of neuronal nicotinic receptors may rival the structural complexity of receptors found at the neuromuscular junction and in electroplax tissue. It should be noted, however, that these experiments were performed on parasympathetic, not sensory, neurons and in a different species. Our demonstration of double labeling in individual trigeminal neurons of $\alpha 3$ and $\beta 4$ subunit mRNAs (Fig. 6) satisfies a fundamental prerequisite for the association of these subunits at the protein level. The lack of perfect overlap between the neuronal populations expressing these two subunits again implies that their association might not be exclusive and/or that there may exist other as yet unidentified subunit partners.

A final consideration relates to the physiological role these receptors play in sensory neuronal function. Several reports indicate that nicotine modulates the activity of sensory neurons. For example, electrophysiological studies have demonstrated that nicotine and nicotinic agonists depolarize primary afferent fibers when administered to dorsal root (Sucher et al., 1990) or trigeminal (Liu et al., 1993) sensory neurons in culture. Moreover, certain populations of $\mathrm{C}$-fiber terminals were shown to be activated by acetylcholine or carbachol applied directly to sensory neuron receptive fields in vivo (Tanelian, 1991) or in vitro (Steen and Reeh, 1993). These effects were dose-related and blocked by pretreatment with either $\kappa$-bungarotoxin (Tanelian, 1991) or hexamethonium (Steen and Reeh, 1993), suggesting that nicotinic activation of sensory neurons is receptor-mediated.

Others have shown nicotine-evoked release of the proinflammatory neuropeptide calcitonin gene-related peptide (CGRP) from pulmonary tissue (Lou et al., 1991, 1992; Hua et al., 1993), trachea (Hua et al., 1994; Jinno et al., 1994), or cultures of dorsal root ganglia (Franco-Cereceda et al., 1992). Our findings here, that neuronal nicotinic receptor subunit mRNAs, especially $\alpha 3$ 
and $\beta 4$, are not expressed predominantly in the small-diameter neurons that give rise to nociceptive $\mathrm{C}$ fibers and that contain the majority of neuropeptide in sensory ganglia (for review, see Jessel and Dodd, 1989), suggest that the effects of nicotinic agonists cited above may be indirect. Alternatively, neuropeptide secretion may be mediated by an $\alpha 4 \beta 2$ subtype, which seems to have a broader cellular distribution pattern in the ganglion and which may include $\mathrm{C}$-fiber somata. Indeed, the possibility exists that other subtypes not elucidated here (e.g., $\alpha 7$ or $\alpha 9$ ) may contribute to these effects. Interestingly, however, CGRP seems to have the most pervasive distribution pattern of all neuropeptides identified in sensory ganglia, including $70 \%$ of medium-sized neurons in the rat dorsal root ganglion (Ju et al., 1987). Taken together with the present findings, this would imply that those cells that express neuronal nicotinic receptors and those expressing CGRP may be overlapping at least partially. The ability of nicotinic agonists to modulate the release of neuropeptides such as CGRP suggests that the use of nicotine-containing tobacco products may lead to or modulate the development of neurogenic inflammation.

Collectively, the present data serve to increase the reported diversity of neuronal nicotinic receptor subtype expression in the mammalian nervous system. In conjunction with the literature cited, our results establish a foundation for more rigorous examinations of the structure, function, and regulation of nicotinic receptors found on sensory neurons and should provide some initial clues for understanding the role these receptors play in the cholinergic physiology of vertebrate sensory systems.

\section{REFERENCES}

Anand R, Conroy WG, Schoepfer R, Whiting P, Lindstrom J (1991) Neuronal nicotinic acetylcholine receptors expressed in Xenopus oocytes have a pentameric quaternary structure. J Biol Chem 266:11192-11198.

Angelotti TP, Macdonald RL (1993) Assembly of GABA A receptor subunits: $\alpha_{1} \beta_{1}$ and $\alpha_{1} \beta_{1} \delta_{2 s}$ subunits produce unique ion channels with dissimilar single-channel properties. J Neurosci 13:1429-1440.

Baccaglini PI, Cooper E (1982) Influences on the expression of acetylcholine receptors on rat nodose neurones in culture. J Physiol (Lond) 324:441-451.

Boulter J, Evans K, Goldman D, Martin G, Treco D, Heinemann S, Patrick J (1986) Isolation of a cDNA clone coding for a possible neural nicotinic acetylcholine receptor $\alpha$-subunit. Nature 319:368-374.

Boulter J, Connolly JG, Deneris ES, Goldman D, Heinemann S, Patrick J (1987) Functional expression of two neuronal nicotinic acetylcholine receptors from cDNA clones identifies a gene family. Proc Natl Acad Sci USA 84:7763-7767.

Boulter J, O'Shea-Greenfield A, Duvoisin RM, Connolly JG, Wada E, Jensen A, Gardner PD, Ballivet M, Deneris ES, McKinnon D, Heinemann S, Patrick $\mathbf{J}$ (1990) $\alpha 3, \alpha 5$, and $\beta 4$ : three members of the rat neuronal nicotinic acetylcholine receptor-related gene family form a gene cluster. J Biol Chem 265:4472-4482.

Boyd RT, Jacob MH, McEacheren AE, Caron S, Berg DK (1991) Nicotinic acetylcholine receptor mRNA in dorsal root ganglion neurons. J Neurobiol 22:1-14.

Britto LRG, Rogers SW, Hamassaki-Britto DE, Duvoisin RM (1994) Nicotinic acetylcholine receptors in the ground squirrel retina: localization of the $\beta 4$ subunit by immunohistochemistry and in situ hybridization. Vis Neurosci 11:569-577.

Cauley K, Marks M, Gahring LC, Rogers SW (1996) Neuronal nicotinic receptor genes $\alpha 3, \alpha 4$, and $\beta 2$ and high affinity nicotine binding sites are expressed by P19 embryonal carcinoma cells. J Neurobiol 30:303-314.

Conroy WG, Berg DK (1995) Neurons can maintain multiple classes of nicotinic acetylcholine receptors distinguished by different subunit compositions. J Biol Chem 270:4424-4431.

Cooper E, Couturier S, Ballivet M (1991) Pentameric structure and subunit stoichiometry of a neuronal acetylcholine receptor. Nature 350:235-238.
Deneris E, Connolly J, Boulter J, Wada E, Wada K, Swanson LW, Patrick J, Heinemann S (1988) Primary structure and expression of $\beta 2$ : a novel subunit of neuronal nicotinic acetylcholine receptor. Neuron 1:45-54.

Deneris ES, Boulter J, Swanson LW, Patrick J, Heinemann S (1989) $\beta 3$ : a new member of nicotinic acetylcholine receptor gene family is expressed in brain. J Biol Chem 264:6268-6272.

Duvoisin RM, Deneris ES, Patrick J, Heinemann S (1989) The functional diversity of the neuronal nicotinic acetylcholine receptors is increased by a novel subunit: $\beta 4$. Neuron 3:487-496.

Elgoyhen AB, Johnson DS, Boulter J, Vetter DE, Heinemann S (1994) Alpha 9: an acetylcholine receptor with novel pharmacological properties expressed in rat cochlear hair cells. Cell 79:705-715.

Flores CM, Rogers SW, Pabreza LA, Wolfe BB, Kellar KJ (1992) A subtype of nicotinic cholinergic receptor in rat brain is composed of $\alpha 4$ and $\beta 2$ subunits and is up-regulated by chronic nicotine treatment. Mol Pharmacol 41:31-37.

Flores CM, Goldstein ME, Gainer H (1993) CPE, PAM, PC1, and PC2 mRNAs are expressed in substance $P$ and CGRP containing neurons of the rat trigeminal ganglion. Soc Neurosci Abstr 19:1361.

Franco-Cereceda A, Rydh M, Dalsgaard D (1992) Nicotine- and capsaicin-, but not potassium-evoked CGRP release from cultured guinea pig spinal ganglia is inhibited by ruthenium red. Neurosci Lett 137:72-74.

Goldman D, Deneris ES, Luyten W, Kochar A, Patrick J, Heinemann S (1987) Members of a nicotine acetylcholine receptor gene family are expressed in different regions of the mammalian central nervous system. Cell 48:965-973.

Goldstein ME, House SB, Gainer H (1991) NF-L and peripherin immunoreactivities define distinct classes of rat sensory ganglion cells. J Neurosci Res 30:92-104.

Harper AA, Lawson SN (1985) Conduction velocity is related to morphological cell type in rat dorsal root ganglion neurons. J Physiol (Lond) 359:31-46.

Houghtling RA, Davila-Garcia MI, Hurt S, Kellar KJ (1994) $\left[{ }^{3} \mathrm{H}\right]-$ Epibatidine binding to nicotinic cholinergic receptors in brain. Med Chem Res 4:538-546.

Houghtling RA, Davila-Garcia MI, Kellar KJ (1995) Characterization of $\left[{ }^{3} \mathrm{H}\right]$-epibatidine binding to nicotinic cholinergic receptors in rat and human brain. Mol Pharmacol 48:280-287.

Hua X-Y, Chiang E, Yaksh T (1993) Sympathetic activation is invoked in nicotine- but not capsaicin- and bradykinin-induced CGRP release from the rat trachea. Soc Neurosci Abstr 19:1368.

Hua X-Y, Jinno S, Back SM, Tam EK, Yaksh TL (1994) Multiple mechanisms for the effects of capsaicin, bradykinin, and nicotine on CGRP release from tracheal afferent nerves: role of prostaglandins, sympathetic nerves, and mast cells. Neuropharmacology 33:1147-1154.

Isenberg KE, Meyer GE (1989) Cloning of a putative neuronal nicotinic acetylcholine receptor subunit. J Neurochem 52:988-991.

Jessel TM, Dodd J (1989) Functional chemistry of primary afferent neurons. In: Textbook of pain (Wall P, Melzack R, eds), pp 82-99. New York: Churchill Livingstone.

Jinno S, Hua X-Y, Yaksh TL (1994) Nicotine and acetylcholine induce release of calcitonin gene-related peptide from rat trachea. J Appl Physiol 76:1651-1656.

Ju G, Hökfelt T, Brodin E, Fahrenkrug P, Fischer JA, Frey P, Elde RP, Brown JC (1987) Primary sensory neurons of the rat showing calcitonin gene-related peptide immunoreactivity and their relation to substance $\mathrm{P}$, somatostatin, galanin, vasoactive intestinal peptide, and cholecystokininimmunoreactive ganglion cells. Cell Tissue Res 247:417-431.

Lamar E, Miller K, Patrick J (1990) Amplification of genomic sequences identifies a new gene, alpha 6 , in the nicotinic acetylcholine receptor gene family. Soc Neurosci Abstr 16:681.

Liu L, Pugh W, Ma H, Simon SA (1993) Identification of acetylcholine receptors in adult rat trigeminal ganglion neurons. Brain Res 617:37-42.

Lou Y-P, Karlsson A, Franco-Cereceda A, Lundberg J (1991) Selectivity of ruthenium red in inhibiting bronchoconstriction and CGRP release induced by afferent $\mathrm{C}$-fibre activation in the guinea pig lung. Acta Physiol Scand 142:191-199.

Lou Y-P, Franco-Cereceda A, Lundberg J (1992) Different ion channel mechanisms between low concentrations of capsaicin and high concentrations of capsaicin and nicotine regarding peptide release from pulmonary afferents. Acta Physiol Scand 146:119-127.

Luthin GR, Harkness J, Artymyshyn RP, Wolfe BB (1988) Antibodies to a synthetic peptide can be used to distinguish between muscarinic acetylcholine receptor binding sites in brain and heart. Mol Pharmacol 34:327-333. 
Mandelzys A, Cooper E, Verge VMK, Richardson PM (1990) Nerve growth factor induces functional nicotinic acetylcholine receptors on rat sensory neurons in culture. Neuroscience 37:523-530.

Munson PJ, Rodbard D (1980) LIGAND, A versatile computerized approach for characterization of ligand binding systems. Anal Biochem 107:220-239.

Parysek LM, Goldman RD (1988) Distribution of a novel 57 kDa intermediate filament (IF) protein in the nervous system. J Neurosci 8:555-563.

Rogers SW, Gahring LC, Papke RL, Heinemann S (1991) Identification of cultured cells expressing ligand-gated cationic channels. Protein Expr Purif 2:108-116.

Rogers SW, Mandelzys A, Deneris ES, Cooper E, Heinemann S (1992) The expression of nicotinic acetylcholine receptors by PC12 cells treated with NGF. J Neurosci 12:4611-4623.

Séguéla P, Wadiche J, Dinely-Miller K, Dani JA, Patrick J (1993) Molecular cloning, functional properties, and distribution of rat brain $\alpha 7$ : a nicotinic cation channel highly permeable to calcium. J Neurosci 13:596-604.

Steen K, Reeh P (1993) Actions of cholinergic agonists and antagonists on sensory nerve endings in rat skin in vitro. J Neurophysiol 70:397-405.

Sucher NJ, Cheng TPO, Lipton SA (1990) Neural nicotinic acetylcholine responses in sensory neurons from postnatal rat. Brain Res 533:248-254.

Sumikawa K, Nishizaki T (1994) The amino acid residues 1-128 in the $\alpha$ subunit of the nicotinic acetylcholine receptor contain assembly signals. Mol Brain Res 25:257-264.
Swanson LW, Simmons DM, Whiting PJ, Lindstrom J (1987) Immunohistochemical localization of neuronal nicotinic receptors in the rodent central nervous system. J Neurosci 7:3334-3342.

Tanelian DL (1991) Cholinergic activation of a population of corneal afferent nerves. Exp Brain Res 86:414-420.

Wada E, Wada K, Boulter J, Deneris E, Heinemann S, Patrick J, Swanson LW (1989) Distribution of alpha-2, alpha-3, alpha-4, and beta-2 neuronal nicotinic receptor subunit mRNAs in the central nervous system: a hybridization histochemical study in the rat. J Comp Neurol 284:314-335.

Wada E, McKinnon D, Heinemann S, Patrick J, Swanson LW (1990) The distribution of mRNA encoded by a new member of the neuronal nicotinic acetylcholine receptor gene family $(\alpha 5)$ in the rat central nervous system. Brain Res 526:45-53.

Wada K, Ballivet M, Boulter J, Connolly G, Wada E, Deneris ES, Swanson LW, Heinemann S, Patrick J (1988) Functional expression of a new pharmacologic subtype of brain nicotinic acetylcholine receptor. Science 240:330-334.

Whiting P, Lindstrom J (1986) Pharmacological properties of immunoisolated neuronal nicotinic receptors. J Neurosci 6:3061-3069.

Whiting P, Lindstrom J (1987) Purification and characterization of a nicotinic acetylcholine receptor from rat brain. Proc Natl Acad Sci USA 84:595-599.

Whiting P, Esch F, Shimasaki S, Lindstrom J (1987) Neuronal nicotinic acetylcholine receptor $\beta$-subunit is coded for by the cDNA clone $\alpha 4$. FEBS Lett 219:459-463. 